\title{
Employment of Persons with Disabilities as Competitive Advantage: An Analysis of the Competitive Implications
}

\author{
Boris MIETHLICH \\ Faculty of Management, Comenius University in Bratislava, Slovakia \\ boris.miethlich@fm.uniba.sk \\ Anett G. OLDENBURG \\ Faculty of Management, Comenius University in Bratislava, Slovakia \\ annet.oldenburg@fm.uniba.sk
}

\begin{abstract}
People with disabilities (PWD) represent a largely untapped market and customer segment worldwide, as well as an enormous untapped workforce potential. Although there are indications in the literature that the employment of PWD can bring many advantages for companies, the effects on companies and the resulting competitive advantages have rarely been empirically investigated. This article aims to analyze the competitive implications of the employment of PWD, as part of the corporate social responsibility (CSR) strategy. The research is based on a literature review. The selected literature was evaluated regarding the competitive advantage using the value-rarityimitability-organisation (VRIO) framework. The results show that the employment of PWD is valuable, rare, and costly to imitate. If a company succeeds in using this resource effectively, this leads to a sustainable competitive advantage. An established corporate culture is a mandatory prerequisite to integrate PWD successfully. This prerequisite represents an imitation barrier. The promotion of the employment of PWD gives access to a new pool of applicants and can contribute to mitigating or preventing a future shortage of skilled workers. The employment of PWD does not wear off as a human resource. The concept can be transferred to different technologies, products, and markets. The sensitivity gained about people with disabilities can open new markets and customer segments. Therefore, PWD's employment as part of the value creation strategy can make a long-term contribution to the company's success and represent a sustainable competitive advantage.
\end{abstract}

Keywords: CSR, Persons with disabilities, Diversity, Employment, HRM

\section{Introduction}

In the western world, there is a clearly distinct and deeply rooted cultural bias towards persons with disabilities (PWD), which can be traced back to antiquity (Gleeson, 1999). Despite great progress, prejudices can still be observed in various forms today. That is particularly evident in debates on abortion and euthanasia (Barnes, 2003). The disability of most PWD is not directly visible as only a small portion is physically disabled (Niehaus, 1997). People with non-obvious disabilities, such as mental or psychological disabilities or those who suffer from chronic pain, are more likely to be confronted with distrust of their willingness to perform compared to people with obvious disabilities (Braun and Niehaus, 1988). Hence, there are still obvious real and mentally constructed barriers to the employment and occupation of people with disabilities (Hidegh and Csillag, 2013; Schur, Kruse and Blanck, 2005).

It is estimated that 10 to 20 percent of the population in each country is affected by disability (Collins, 2007). Simultaneously, this population share is an enormous untapped labor potential worldwide (Buys, Matthews and Randall, 2015) as well as a largely untapped market for products and services (Collins, 2007). If companies want to exploit this potential and be successful in this 
market segment, it requires, as in any other segment, a clear understanding of the needs of the market. Only if customer needs are met effectively, profitably, and better than by competitors a real competitive advantage can be created (Papulova and Papulova, 2006). A commitment to the employment of PWD can help develop a better understanding of the needs and concerns of customers with disabilities (Miethlich, 2018; Seino et al., 2017). Till this day, PWD with the same professional qualifications as persons without disabilities, have lower career prospects (Lindsay et al., 2018; Berthoud, 2008) and are disproportionately affected by unemployment (Markel and Barclay, 2009). Therefore, the promotion of employment and inclusion of PWD is an important social responsibility that must be addressed in the CSR strategy of companies (Miethlich and Slahor, 2018b; Monachino and Moreira, 2014; Kuznetsova, 2012; Markel and Barclay, 2009). By addressing this social responsibility, companies can benefit from advantages resulting from their reputation as good corporate citizens or socially responsible companies (Miethlich and Slahor, 2018a) as well as strengthening value drivers such as the development of a differentiated reputation with key stakeholders and customers (Gröschl, 2005). Actual "disability champions", i.e., companies that could serve as role models for business cases and best practices for other companies, are largely absent (Fasciglione, 2015; Hernandez et al., 2008). Positive examples are important to demonstrate and understand the benefits of such activities (Wehman, 2011; Markel and Barclay, 2009; Hernandez et al., 2008).

The integration of people with disabilities in the company must be understood as a standardized process that aims to promote employment of PWD under the same conditions as other workers (Munduate et al., 2014). The main element in the proactive employment of people with disabilities is the reduction of mental and physical barriers within the company (Miethlich and Slahor 2018b, Hidegh and Csillag, 2013; Markel and Barclay, 2009; Schur et al., 2005). It is necessary to create a disability-friendly corporate culture, to promote the employment of PWD. This can be achieved by breaking down prejudices and stereotypes (Houtenville and Kalargyrou, 2012), raising the awareness of all employees (Bengisu and Balta, 2011; Houtenville and Kalargyrou, 2012; Segovia-San-Juan, Saavedra and Fernández-de-Tejada, 2017) as well as by continuous signals from the top management to integrate PWD into the company (Ball et al., 2005; Schur et al., 2005). To support this process, the evaluation and reward systems of managers can include the treatment of PWD as a criterion and provide resources and incentives for employees to mentor and train PWD or to engage in job adaptation (Schur et al., 2005).

So far, there are only a few studies that deal with the possible competitive advantages of the employment of PWD. The advantages and possible competitive advantages identified in the literature often seem to focus on the same, few aspects. The article aims to present the current state of research on competitive advantages resulting from the employment of PWD in a concise form as well as to analyze the resulting competitive implications.

\section{Competitive Advantages and Implications}

Competitive advantage arises when a company implements a value creation strategy that is not simultaneously implemented by competitors. However, a sustainable competitive advantage only emerges if the competitors are not able to imitate this value creation strategy and if the competitive advantage is not compromised by the imitation attempts themselves. In practice, competitive advantages that can be hardly imitated are mostly based on the unique history of the company, the social complexity, and causal ambiguity, i.e., the lack of transparency for the success-critical connections of resources (Barney, 1991). A company's resources and capabilities are the most reliable and lasting basis for developing competitive strategies, especially in a constantly changing environment. Resources and capabilities must therefore not only be taken into account in strategy development but also renewed and maintained as part of corporate strategy (Grant, 1991). Companies achieve a competitive advantage specifically if they implement a "value creating strategy" which is not implemented by a potential competitor simultaneously and cannot be imitated easily. If the 
strategy were to be imitated later, the company would generally still benefit from a "first mover advantage" (Barney, 1991).

The generic strategic principles for achieving a competitive advantage are divided into three fundamental types: the strategy of cost leadership, the strategy of differentiation and the strategy of focus (Porter, 2008). In economics literature, these are generally used under the term competitive strategies, since their aim is to achieve and secure a lasting competitive advantage (Kerth, Asum and Stich, 2015). The resource-based view (RBV) provides a methodological approach to analyze the factors of competitive advantages in terms of resources and capabilities and to develop strategies for sustainable competitive advantages (Barney, 1991; Grant, 1991). The principle for achieving competitive advantage is that the resources used should be relatively rare, valuable, immobile, heterogeneously distributed across competing companies, difficult to imitate and not substitutable. According to this theory, companies with similar resources would have the same productivity and thus no sustainable competitive advantage (Houtenville and Kalargyrou, 2012). The identification and better use of corporate resources are therefore essential. Only if a company can make better use of its resources and capabilities than its competitors, it can achieve a real competitive advantage and higher profitability (Wells, 2008; Gröschl, 2005; Barney, 1991). A competitive advantage can be achieved through a differentiation strategy based on superior quality, superior knowledge of customer needs, superior product innovations, unique knowledge, or a unique reputation (Dubs et al., 2004).

Resources can be understood as all assets, abilities, organizational processes, characteristics, information, knowledge, etc., which are controlled by a company and which enable the company to develop and implement strategies as well as to improve efficiency and effectiveness (Barney, 1991). Resources can be categorized as physical capital resources (e.g., technology, real estate, geographical location), organizational capital resources (e.g., processes, controlling, organizational structures), and human capital resources (e.g., experience, diversity, intelligence, corporate culture) (Barney, 1991). Human capital resources are of particular importance because they do not wear out and can be transferred to different technologies, products, and markets (Wright, McMahan and McWilliams, 1994). In most cases, it is not possible to derive clear causal relationships between resources and competitive advantages (Barney, 1991) or the influence of resources on the success of the company (Penrose, 2009). However, it is not enough to evaluate the individual resources of a company isolated to give a company a competitive advantage. The synergistic combination and integration as well as the bundling of resources leads to a sustainable competitive advantage (Rashidirad, Soltani, Salimian and Liao, 2015; Black and Boal, 1994) and constitute the uniqueness of a company (Penrose, 2009).

Nevertheless, not all resources contribute to the generation of competitive advantages. To identify resources that can contribute to generating sustainable competitive advantages, the following attributes are empirical indicators: "It must be valuable, in the sense that it exploit opportunities and/or neutralizes threats in a firm's environment, it must be rare among a firm's current and potential competition, it must be imperfectly imitable, and there cannot strategically equivalent substitutes for this resource that are valuable but neither rare or imperfectly imitable." (Barney, 1991, p. 106). The Barney value-rarity-imitability-organisation (VRIO) framework assesses the resources and capabilities of organizations and the resulting potential for competitive advantage based on the following four criteria: Value, rarity, imitability, and exploitation by the organization. The VRIO framework is shown below (Table 1): 
Education Excellence and Innovation Management through Vision 2020

Table 1: The VRIO framework, according to Barney and Clark (2007)

\begin{tabular}{|c|c|c|c|c|c|}
\hline Valuable? & Rare? & $\begin{array}{l}\text { Costly } \\
\text { to imitate? }\end{array}$ & $\begin{array}{l}\text { Exploited by } \\
\text { organization? }\end{array}$ & $\begin{array}{l}\text { Competitive } \\
\text { implications }\end{array}$ & $\begin{array}{l}\text { Economic } \\
\text { performance }\end{array}$ \\
\hline No & - & - & No & Disadvantage & Below normal \\
\hline Yes & No & - & $\overline{4}$ & Parity & Normal \\
\hline Yes & Yes & No & $\nabla$ & Temporary advantage & Above normal \\
\hline Yes & Yes & Yes & Yes & Sustained advantage & Above normal \\
\hline
\end{tabular}

It is important that the management has assurance about the skills and resources available in the company or network. Otherwise, the danger of failure in transforming an idea into a new business model or its implementation due to a lack of or inappropriate resources and skills is great. To achieve a sustainable competitive advantage, the management should focus on resources and capabilities, that competitors cannot or can only imitate with difficulty, such as unusual expertise, specific process knowledge, corporate image or a strong brand (Doleski, 2015). Particularly social phenomena can hardly be imitated, and companies themselves can hardly systematically manage and influence social complexity (Barney, 1991). It is also difficult for competitors to identify this source of competitive advantage (Wright et al., 1994; Barney, 1991). Due to other prerequisites, the imitation of success potentials of another company hardly leads to a source of sustainable competitive advantages of its own (Ridder and Bruns, 2002).

The approaches and methods of Human Resource Management (HRM) do not themselves represent a source of sustainable competitive advantages, also along with the VRIO framework, since methods and approaches are rather easily imitable or substitutable and are not uncommon (Wright et al., 1994). Nevertheless, HRM plays an important role when it comes to generating sustainable competitive advantages from human resources and exploiting these potentials (McMahan, Virick and Wright, 1999; Wright et al., 1994). Human capital resources that influence competitive advantage include interpersonal relationships, corporate culture, employee motivation, and reputation among employees, suppliers, and customers (Barney, 1991). Overall, motivated and committed employees enable better use of existing resources (Dubs et al., 2004).

\section{CSR as a Competitive Advantage}

There are few empirical studies on the impact of CSR activities on business success (Wang et al., 2016; Peloza and Shang, 2011). Those previous investigations have shown inconsistent results (Kraus and Brtitzelmaier, 2012; Peloza and Shang, 2011; Park and Lee, 2009). These results could partly be explained by the qualitative factors that, directly or indirectly, contribute to the added value of a company. These qualitative factors are very difficult to measure and quantify (Miller and Ahrens, 1993). In analytical terms, the resource-based perspective shows that CSR clearly leads to a competitive advantage (Branco and Rodrigues, 2006). In business practice, managers have also recognized that a socially responsible reputation has a positive influence on business success (Matten and Crane, 2007). Simultaneously, CSR offers a way of differentiation, especially with the possibility to achieve an important, unique, and superior position in the market (Boehe and Cruz, 2010; Anselmsson and Johansson, 2007). A strong brand makes a significant contribution to the success of a company (Anselmsson, Bondesson and Melin, 2016). CSR activities can bring a company competitive advantages when new customer benefits can be increased or created successfully (Chen et al., 2018; Peloza and Shang, 2011). For example, a holistic strategy, that focuses on sustainability aspects in all business activities, can bring a competitive advantage through differentiation and innovation. That offers stakeholders, and specifically customers, a unique value proposition (Baumgartner and Ebner, 2010). 


\section{Resources and skills through the employment of PWD}

Various research results indicate that the employment of PWD has many positive influences on a company and can contribute to its success. In corporate practice, positive effects on costeffectiveness, employee turnover, and retention, reliability, employee loyalty, motivation, and company image were observed. Further, advantages can also arise through various customers, customer loyalty and satisfaction, innovation, productivity, work ethic, work safety, inclusive work culture, and ability awareness (Lindsay et al., 2018). Furthermore, the employment of PWD can help to avoid legal problems and reduce the risk of legal aggravation (Othman and Sorial, 2017; Hartnett et al., 2011) and attacks through media, NGOs, and other stakeholders (Csillag and Gyori, 2016).

The sensitivity to disability allows companies to develop products and services for PWD which could address new market segments. The employment of PWD, as well as the consideration of PWD as customers, brings various business opportunities. Companies should respond to the needs of customers with disabilities, as they may need specially designed products and services to be able to use them (Csillag, Gyori and Matolay, 2018; Miethlich, 2018). A company can develop a comprehensive understanding of the needs and concerns of customers with disabilities by employing PWD or engaging in vocational rehabilitation (Seino et al., 2017). That can increase employees' awareness of disability (Lindsay et al., 2018), which subsequently promotes innovation (Ball et al., 2005) and the development of "designed-for-all" products and services (Kuznetsova, 2012). The employment of PWD gives an opportunity to attract and retain socially responsible customers and customers with disabilities (Lindsay et al., 2018).

However, companies usually use or understand the employment of PWD as a means of promoting their image and not as a direct competitive advantage. The employment of PWD reflects the diversity in the consumer market, which leads to a competitive advantage (Dibben, James, Cunningham and Smythe, 2002) and allows to obtain competitive advantages such as the creation of value. That results in higher profits (Gelashvili, Camacho-Miñano and Segovia-Vargas, 2015) which can be confirmed by various practical examples (Kalargyrou, 2014). Vocational rehabilitation or disability management, i.e., the return of sick employees to suitable work, can also bring advantages for companies. These advantages can be divided into three categories: Increase productivity, reduce personnel costs, and maintain the return on human capital. The faster an impaired employee can return to work, the less disruption he or she will have to endure. If an affected employee can be retained in the company, the fluctuation rate decreases and therefore also the personnel costs (e.g., recruitment, selection, employment, and training of a substitute employee). Losing an employee due to an illness or accident reduces the "return-on-investment" (Dean, 1988).

After a successful vocational rehabilitation, affected employees are above-average committed and loyal (Dean, 1988). A positive social response to disability in the workplace reduces the stigma and threat of job loss associated with it. Employees who learn how the company cares for sick or injured colleagues seem to have better resilience. Studies also point to the fact that the existence of disability management or a vocational rehabilitation program in a company is accompanied by less workrelated burnout cases and an improved corporate culture as well as a positive influence on the job satisfaction of the persons concerned and their colleagues (Wagner et al., 2017). Vocational rehabilitation is also an interesting way of recruiting and retaining staff (Miethlich and Slahor, 2018a). The employment of PWD has similar advantages in this respect (Miethlich, 2018). PWD are very loyal and committed employees and change jobs less often, reducing staff turnover. In addition, PWD are an integral part of a diverse workforce (Houtenville and Kalargyrou, 2015). Psychological work safety seems to be increased by the competitive employment of PWD, which can lead to higher motivation of all employees, less personnel fluctuation, higher overall profitability, and results in a competitive advantage (Kalargyrou, 2014). This untapped pool of applicants can also be a solution to a future shortage of skilled workers (Ball et al., 2005). Furthermore, the integration of PWD into the company improves the corporate culture and strengthens the employer brand (Csillag et al., 2018). 
The promotion of PWD employment, as well as vocational rehabilitation, serve as an added value for a company's social responsibility program (Millington et al., 2003), minimize social and health costs for society in the long term and secure the professional future of those affected. Companies that commit themselves can generate an actual "shared value" since the prosperity of the society is increased which will benefit the company in return (Miethlich and Slahor, 2018a; Papula, Papulová and Papula, 2014). To be prepared for the consequences and challenges of demographic change, an aging workforce, and more people with chronic illnesses as well as an increasing shortage of skilled workers, the employment of PWD and vocational rehabilitation should be an integral part of every company's human resource management (Niehaus and Marfels, 2010). In addition, the targeted use of PWD with specific disabilities can achieve a leverage effect based on their strengths (Friedner, 2013); for example, autistic people who provide top performance in troubleshooting software development, deaf people through their more pronounced sense of taste than chefs or master brewers, blind people with a pronounced sense of touch as physiotherapists or masseurs, people with learning disabilities with their constant friendly and positive attitude in direct contact with customers or people with mental or learning disabilities who can persevere in performing the same simple, repetitive manual tasks over a long period of time.

\section{Methodology}

The aim of this study is to analyze the representative literature regarding the competitive implications of the employment of PWD, as part of the CSR strategy. The expected results are indications of whether the employment of PWD could be a sustainable competitive advantage and how it connects to the value creation strategy of a company. The research was conducted by searching the scientific databases Web of Science and Scopus for published literature since 2000 in the subject areas of business, economics, and management using the following keywords: social inclusion, disability, disability management, and employment of persons with disabilities. Additionally, the reference lists of all previously selected articles were checked to find further studies. The titles, abstracts, and keywords of papers were scanned to identify papers related to competitive advantage and employment of PWD. For the in-depth analysis, English articles published in peer-reviewed journals, conference proceedings or books were selected. The findings in the literature were evaluated regarding the competitive implication using the VRIO framework (Barney and Clark, 2007).

\section{Analysis using the VRIO framework}

The resources and capabilities identified from the effects of the employment of PWD are evaluated using the VIRO framework according to the criteria: Valuable, rare, costly to imitate, and exploited by organizations.

Valuable: Does the employment of PWD translate directly or indirectly to customer value and/or neutralize an environmental threat? The employment of PWD offers companies a competitive advantage in the form of a source of qualified, dedicated and loyal employees. This untapped pool of applicants can also be a solution to a future shortage of skilled workers. PWD's employment is a central element of corporate social responsibility and makes a significant contribution to promoting the company's reputation through CSR initiatives. Furthermore, the company demonstrates its flexibility and progressiveness, especially regarding (existing) employees, and leads to a growth of the corporate culture. The sensitivity to the topic of disability also promotes innovation. Simultaneously, the commitment can create a shared value, based on added value for both the company and society. There is a win-win situation for all participants, which in turn increases the value of the company. The promotion of the employment of PWD allows offering stakeholders and specifically customers a unique value proposition. Additionally, legal issues are avoided, reducing the risk of legal aggravation and attacks on the company by the media, NGOs and other stakeholders. 
Rare: Can the employment of PWD be accessed easily from elsewhere? Only a few companies proactively employ PWD. Although the characteristics vary from sector to sector, there are no "disability champions" that can serve as role models. The proactive employment and the use of competences of PWD are further differentiating features that are advantageous especially in the HRM sector, which is characterized by a high level of competition. They offer the company the opportunity to achieve a unique competitive advantage. One of the necessary preconditions is the grown corporate culture, which cannot be imitated quickly by competitors, which makes (fast) copying more difficult. This fact offers the company advantages by a first mover strategy to build market entry barriers, to secure and use market shares. The strategic integration of the employment of PWD into strategic HRM and corporate management only takes place in very few companies. Accordingly, the successful integration of PWD can be classified as "rare".

Costly to imitate: Are there imitation barriers to the employment of PWD? The generation of core competencies involves a finely tuned bundling of diverse activities, which in turn lead to a unique resource and superior competence over the competition. It requires an effective method to generate and sustain these. This fact makes it more difficult for potential competitors to enter the market and constitutes a significant imitation barrier. Nevertheless, these possibilities are principally open to every company. It turns out that companies that have existed for a long time, have wealth, and created a developed corporate culture proactively employ PWD. Achieving a diverse and inclusive corporate culture is a long process. The reduction of physical and mental barriers is in the foreground. The costs of reducing physical barriers are often covered by governmental incentives and subventions or insurance contracts. Also, most of the necessary workplace adjustments to employ PWD are cost effective. Breaking down mental barriers in the company is comparatively time-consuming. It is possible to eliminate any prejudices against PWD that may exist in this context, but this requires an active, skillful management strategy to be successfully implemented in the medium to long term. If a successful integration into the organization is successful, this can result in a competitive advantage. Furthermore, PWD cannot be so easily replaced by other groups, methods or approaches of diversity in the company, which keeps the threat of substitutes at a low level and continues to represent a sustained competitive advantage and a high level of imitation protection.

Exploited by the organization: How can companies use this "resource" for themselves? The use of resources and skills of PWD requires the employment of PWD and the promotion of equal opportunities within the company. Companies can employ and benefit from PWD with manageable adjustments to the organization (e.g., adjustments to the workplace, flexible working time models, functional profiles). For PWD to develop their full potential, an appropriate corporate culture is a prerequisite. A disability-friendly corporate culture can be created by reducing prejudices and stereotypes. Continuous signals from top management as well as incentives for managers and employees regarding mentoring and training of PWD are essential. Overall greater employee motivation and commitment lead to better utilization of the existing resources. If these constraints are considered, a corporate structure is created which enables the effective use of PWD as a resource. Ultimately, the successful implementation and long-term benefit require a coordinated interaction and embedding in all areas of the company.

The brief analysis using the VRIO framework shows that the employment of PWD, as part of the CSR strategy, can be classified as valuable, rare and costly to imitate. If a company succeeds in using this resource effectively and better than its competitors, it can lead to a real sustainable competitive advantage and as a result to a strong competitive position.

\section{Conclusion}

The aim of this article was to reflect the current state of research on the resulting competitive advantages for companies through the employment of PWD and to derive the effects on competition as well as implications for the company. That was done from a generalized view of the current 
research results and based on the RBV. As a result of this work, the statement can be made that the employment of PWD represents a clear competitive advantage for companies.

The analysis based on the VRIO framework shows that the employment of PWD can be classified as valuable, rare and costly to imitate and if a company succeeds in using this resource effectively it leads to a sustainable competitive advantage. The analysis also indicates that HRM itself is not a source of sustainable competitive advantages but offers a temporary competitive advantage. Therefore, the imitation is possible but difficult. It is impossible to imitate or transfer the use of resources 1:1. The existence of certain conditions, such as an established corporate culture, is a mandatory prerequisite for the integration of PWD into the workforce and thus for the success of the strategy and the utilization of this resource. It is an organizational process in which the workforce and corporate culture influence and develop each other. The points mentioned show imitation barriers that could simultaneously point to a reason for the below-average employment of PWD. If one considers HRM in the task of generating sustainable competitive advantages from human resources and the use of these potentials, its importance becomes visible. What can be deduced from the results regarding the question of the effect on the competition? If the competitive advantage is regarded as temporary, clear advantages can be derived from the pioneering strategy regarding the use of resources ("first mover advantage"). However, even in that case, niche strategies create a sustainable competitive advantage. For example, employees with disabilities are more committed, motivated, loyal to the company, and generally more satisfied with their work. The resulting advantages for the company, such as increased productivity, lead to higher overall profitability and thus to a competitive advantage. Besides that, the consideration and promotion of the employment of PWD allows to access a bigger pool of applicants and can thus contribute to mitigating or preventing a future shortage of skilled workers. The sensitivity gained about people with disabilities can also give access to additional markets and customer segments. With this important social commitment, the possibility of differentiation can also be understood as a strategy to achieve a unique and superior position in the market. Overall, the employment of PWD offers a positive contribution to the company's success. This potential is currently not exploited to its full potential. The employment of PWD does not wear off as a human resource and can be transferred to different technologies, products, and markets. Therefore, the employment of PWD, as part of the value creation strategy, can make a long-term contribution to the company's success and represents a sustainable competitive advantage.

\section{References}

Anselmsson, J. and Johansson, U. (2007), 'Corporate social responsibility and the positioning of grocery brands: An exploratory study of retailer and manufacturer brands at point of purchase', International Journal of Retail \& Distribution Management, 35 (10), 835-856.

Anselmsson, J., Bondesson, N. and Melin, F. (2016), 'Customer-based brand equity and human resource management image: Do retail customers really care about HRM and the employer brand?', European Journal of Marketing, 50 (7/8), 1185-1208.

Ball, P., Monaco, G., Schmeling, J., Schartz, H. and Blanck, P. (2005), 'Disability as diversity in fortune 100 companies', Behavioral Sciences and the Law, 23 (1), 97-122.

Barnes, C. (2003), 'Rehabilitation for disabled people: a 'sick'joke?', Scandinavian Journal of Disability Research, 5 (1), 7-23.

Barney, J. B. (1991), 'Firm Resources and Sustained Competitive Advantage', Journal of Management, 17 (1), 99-120.

Barney, J. B. and Clark, D. N. (2007), Resource-based theory: Creating and sustaining competitive advantage, Oxford University Press on Demand, Oxford. 
Baumgartner, R. J. and Ebner, D. (2010), 'Corporate sustainability strategies: sustainability profiles and maturity levels', Sustainable Development, 18 (2), 76-89.

Bengisu, M. and Balta, S. (2011), 'Employment of the workforce with disabilities in the hospitality industry', Journal of Sustainable Tourism, 19 (1), 35-57.

Berthoud, R. (2008), 'Disability employment penalties in Britain', Work, Employment and Society, 22 (1), 129-148.

Black, J. A. and Boal, K. B. (1994), 'Strategic resources: Traits, configurations and paths to sustainable competitive advantage', Strategic Management Journal, 15 (S2), 131-148.

Boehe, D. M. and Cruz, L. B. (2010), 'Corporate Social Responsibility, Product Differentiation Strategy and Export Performance', Journal of Business Ethics, 91 (S2), 325-346.

Branco, M. C. and Rodrigues, L. L. (2006), 'Corporate Social Responsibility and Resource-Based Perspectives', Journal of Business Ethics, 69 (2), 111-132.

Braun, H. and Niehaus, M. (1988), Die soziale Situation schwerbehinderter Erwerbspersonen - Eine explorative Studie in Rheinland-Pfalz, Ministerium für Soziales und Familie Rheinland-Pfalz.

Buys, N., Matthews, L. R. and Randall, C. (2015), 'Contemporary vocational rehabilitation in Australia', Disability and rehabilitation, 37 (9), 820-824.

Chen, X., Huang, R., Yang, Z. and Dube, L. (2018), 'CSR types and the moderating role of corporate competence', European Journal of Marketing, 52 (7/8), 1358-1386.

Collins, A. B. (2007), Opportunities and Obligations in Dealing with the Disabled Staff and Customers in Hospitality Industry, Tourism Management in the 21st Century, Chang, P. R. (ed), Nova Science Publishers Inc., New York.

Csillag, S. and Gyori, Z. (2016), "'Is there a place for me?" Employment of people with disabilities as part of csr strategy', Proceedings of the $4 \mathrm{~h}$ Strategica International Academic Conference: Opportunities and risks in the contemporary business environment, ISBN: 978-606-749-181-4, 20-21 October 2016, Bucharest, Romania, 860-872.

Csillag, S., Gyori, Z. and Matolay, R. (2018), Two Worlds Apart? Corporate Social Responsibility and Employment of People with Disabilities, The Critical State of Corporate Social Responsibility in Europe (Critical Studies on Corporate Responsibility, Governance and Sustainability, Volume 12), Tench, R., Jones, B. and Sun, W. (ed), Emerald Publishing Limited, Bingley.

Dean, D. (1988), 'Costs and benefits of vocational rehabilitation: an employer's perspective', Employment Relations Today, 15 (2), 141-147.

Dibben, P., James, P., Cunningham, I. and Smythe, D. (2002), 'Employers and employees with disabilities in the UK: An economically beneficial relationship?', International Journal of Social Economics, 29 (6), 453-467. 
Doleski, O. D. (2015). Integrated Business Model: Applying the St. Gallen Management Concept to Business Models, Springer Gabler, Wiesbaden.

Dubs, R., Euler, D., Rüegg-Stürm, J. and Wyss, C. (2009), Einführung in die Managementlehre, Haupt, Bern.

Fasciglione, M. (2015), Corporate social responsibility and the right to employment of persons with disabilities, Protecting the rights of people with autism in the fields of education and employment, Della Fina, V. and Cera, R. (ed), Springer, Cham.

Friedner, M. (2013), 'Producing "Silent Brewmasters": Deaf workers and added value in India's coffee cafés', Anthropology of Work Review, 34 (1), 39-50.

Gelashvili, V., Camacho-Miñano, M. M. and Segovia-Vargas, M. (2015), 'The Profitability of Socially Reponsible Companies: Public Subsidies for Sheltered Employment Centers', Ramon Llull Journal of Applied Ethics, (6), 111-123.

Gleeson, B. (1999), Geographies of Disability, Routledge, London.

Grant, R. M. (1991), 'The Resource-Based Theory of Competitive Advantage: Implications for Strategy Formulation', California Management Review, 33 (3), 114-135.

Gröschl, S. (2005), 'Persons with Disabilities: A Source of Nontraditional Labor for Canada's Hotel Industry', Cornell Hotel and Restaurant Administration Quarterly, 46 (2), 258-274.

Hartnett, H. P., Stuart, H., Thurman, H., Loy, B. and Batiste, L. C. (2011), 'Employers' perceptions of the benefits of workplace accommodations: Reasons to hire, retain and promote people with disabilities', Journal of Vocational Rehabilitation, 34 (1), 17-23.

Hernandez, B., McDonald, K., Divilbiss, M., Horin, E., Velcoff, J. and Donoso, O. (2008), 'Reflections from employers on the disabled workforce: focus groups with healthcare, hospitality and retail administrators', Employee Responsibilities and Rights Journal, 20 (3), 157-164.

Hidegh, A. L. and Csillag, S. (2013), 'Toward "mental accessibility": changing the mental obstacles that future Human Resource Management practitioners have about the employment of people with disabilities', Human Resource Development International, 16 (1), 22-39.

Houtenville, A. and Kalargyrou, V. (2012), 'People with Disabilities: Employers' Perspectives on Recruitment Practices, Strategies, and Challenges in Leisure and Hospitality', Cornell Hospitality Quarterly, 53 (1), 40-52.

Houtenville, A. and Kalargyrou, V. (2015), 'Employers' perspectives about employing people with disabilities: A comparative study across industries', Cornell Hospitality Quarterly, 56 (2), 168-179.

Kalargyrou, V. (2014), 'Gaining a competitive advantage with disability inclusion initiatives', Journal of Human Resources in Hospitality \& Tourism, 13 (2), 120-145. 
Kerth, K., Asum, H. and Stich, V. (2015), Die besten Strategietools in der Praxis: Welche Werkzeuge brauche ich wann? Wie wende ich sie an? Wo liegen die Grenzen?, Carl Hanser Verlag GmbH Co KG, München.

Kraus, P. and Brtitzelmaier, B. (2012), 'A literature review on corporate social responsibility: definitions, theories and recent empirical research', International Journal of Management Cases, 14 (4), 282-296.

Kuznetsova, Y. (2012), 'Inclusive corporate culture and employment of persons with disabilities: analysis of CSR strategies of multinational enterprises in Norway and the UK', Proceedings of the 13th UFHRD International Conference on Human Resource Development Research and Practice Across Europe: The future of HRD - 2020 and beyond: challenges and opportunities, 23-25 May 2012, Famalicao, Portugal.

Lindsay, S., Cagliostro, E., Albarico, M., Mortaji, N. and Karon, L. (2018), 'A Systematic Review of the Benefits of Hiring People with Disabilities', Journal of Occupational Rehabilitation, 28 (4), 634655 .

Markel, K. S. and Barclay, L. A. (2009), 'Addressing the underemployment of persons with disabilities: Recommendations for expanding organizational social responsibility', Employee Responsibilities and Rights Journal, 21 (4), 305-318.

Matten, D. and Crane, A. (2007). Business Ethics. In A to Z of Corporate Social Responsibility - A Complete Reference Guide to Concepts, Codes and Organisations, Visser, W., Matten, D. and Böhmer, K. (ed), John Wiley \& Sons Ltd, Chichester.

McMahan, G. C., Virick, M. and Wright, P. M. (1999), 'Alternative theoretical perspectives for strategic human resource management revisited: Progress, problems, and prospects', Research in personnel and human resource management, 4 (1), 99-122.

Miethlich, B. (2018), 'Comparing the impact of employment of persons with disabilities and vocational rehabilitation on companies', Proceedings of the 10th Biannual CER Comparative European Research Conference - International Scientific Conference for Ph.D. students of EU countries, ISBN: 978-0-9935191-9-2, 29-31 October 2018, London, United Kingdom, 43-47.

Miethlich, B. and Šlahor, L. (2018a), 'Creating shared value through implementing vocational rehabilitation in the corporate social responsibility strategy: A literature review', Proceedings of the 32nd IBIMA International Business Information Management Association Conference - Vision 2020: Sustainable Economic Development and Application of Innovation Management from Regional expansion to Global Growth, ISBN: 978-0-9998551-1-9, 15-16 November 2018, Seville, Spain, 1444-1460.

Miethlich, B. and Šlahor, L. (2018b), 'Employment of persons with disabilities as a corporate social responsibility initiative: Necessity and variants of implementation', Proceedings of the 6th CBU International Conference on Innovations in Science and Education, ISBN: 978-80-270-5037-6, 21-23 March 2018, Prague, Czech Republic, 350-355.

Millington, M. J., Miller, D. M., Asner-Self, K. K. and Linkowski, D. (2003), The business perspective on employers, disability, and vocational rehabilitation, Work and disability, Szymanski, E. and Parker, R. (ed), PRO-ED, Austin. 
Miller, F. D. and Ahrens, J. (1993), The social responsibility of corporations, Business Ethics: A Philosophical Reader, White, T. I. (ed), Prentice Hall, New Jersey.

Monachino, M. S. and Moreira, P. (2014), 'Corporate social responsibility and health promotion debate: An international review on the potential role of corporations', International Journal of Healthcare Management, 7 (1), 53-59.

Munduate, L., Di Marco, D., Martinez-Corts, I., Arenas, A. and Gamero, N. (2014), 'Rebuilding the social dialogue and promoting inclusive organizations. A tool for social innovation in times of crisis', Papeles Del Psicólogo, 35 (2), 122-129.

Niehaus, M. (1997), Barrieren gegen die Beschäftigung langfristig arbeitsloser Behinderter, Behinderte auf dem Arbeitsmarkt: Wege aus dem Abseits, Niehaus, M. and Montada, L. (ed), Campus Verlag, Frankfurt.

Niehaus, M. and Marfels, B. (2010), 'Competencies and tasks of disability management professionals in Germany', International Journal of Disability Management, 5 (2), 67-72.

Othman, A. A. E. and Sorial, M. H. H. (2017), 'Achieving competitive advantage through the integration of disabled architects in architectural design firms in Egypt', Organization, Technology and Management in Construction: an International Journal, 9 (1), 1547-1558.

Papula, J., Papulová, Z. and Papula, J. (2014), Konkurenčné stratégie: tradičné prístupy vs. nové pohl'ady a techniky, Wolters Kluwer, Bratislava, Slovak Republic.

Papulova, E. and Papulova, Z. (2006), 'Competitive strategy and competitive advantages of small and midsized manufacturing enterprises in Slovakia', E-Leader Slovakia, 1-6.

Park, S. Y. and Lee, S. (2009), 'Financial rewards for social responsibility: A mixed picture for restaurant companies', Cornell Hospitality Quarterly, 50 (2), 168-179.

Peloza, J. and Shang, J. (2011), 'How can corporate social responsibility activities create value for stakeholders? A systematic review', Journal of the Academy of Marketing Science, 39 (1), 117-135.

Penrose, E. (2009), The Theory of the Growth of the Firm. Oxford university press, Oxford.

Porter, M. E. (2008), Competitive strategy: Techniques for analyzing industries and competitors, Free Press, New York.

Rashidirad, M., Soltani, E., Salimian, H. and Liao, Y. (2015), 'The applicability of Grant's framework in the dynamic digital age', European Business Review, 27 (6), 656-678.

Ridder, H. G. and Bruns, H. J. (2002), Strategische Personalentwicklung und nachhaltige Wettbewerbsvorteile - Kompetenzmanagement aus ressourcenorientierter Sicht, Personalentwicklung als Kompetenzentwicklung, Becker, M. and Schwertner, A. (ed), Hampp, München.

Schur, L., Kruse, D. and Blanck, P. (2005), 'Corporate culture and the employment of persons with disabilities', Behavioral Sciences \& the Law, 23 (1), 3-20. 
Segovia-San-Juan, A. I., Saavedra, I. and Fernández-de-Tejada, V. (2017), 'Analyzing Disability in Socially Responsible Companies', Social Indicators Research, 130 (2), 617-645.

Seino, K., Nomoto, A., Takezawa, T. and Boeltzig-Brown, H. (2017), The diversity management for employment of the persons with disabilities: evidence of vocational rehabilitation in the united states and japan, Handbook of Research on Human Factors, Contemporary Workforce Development, Christiansen, B. and Chandan, H. C. (ed), Business Science Reference, Hershey.

Wagner, S., Harder, H., Scott, L., Buys, N., Yu, I., Geisen, T., Randall, C., Lo, K., Tang, D., FraessPhillips, A., Hassler, B. and Howe, C. (2017), 'Canadian employee perspectives on disability management', International Journal of Disability Management, 12, E3.

Wang, H., Tong, L., Takeuchi, R. and George, G. (2016), 'Corporate social responsibility: an overview and new research directions thematic issue on corporate social responsibility', Academy of Management Journal, 59 (2), 534-544.

Wehman, P. H. (2011), 'Employment for persons with disabilities: Where are we now and where do we need to go? ', Journal of Vocational Rehabilitation, 35 (3), 145-151.

Wells, S. J. (2008), 'Counting on workers with disabilities', Human Resource Management International Digest, 16 (6), 44-48.

Wright, P. M., McMahan, G. C. and McWilliams, A. (1994), 'Human resources and sustained competitive advantage: a resource-based perspective', International journal of human resource management, 5 (2), 301-326. 